\title{
Formulation, Development and Evaluation of Bisoprolol Sustained Release Tablets
}

\author{
M. Masum ${ }^{1}$, M. A. R. Ripon ${ }^{1}$, D. R. Bhowmik', M. T. Amin ${ }^{1}$, S. Arefin ${ }^{2}$, M. S. Hossain ${ }^{* 1}$ \\ ${ }^{1}$ Department of Pharmacy, Noakhali Science and Technology University, Noakhali-3814, \\ Bangladesh \\ ${ }^{2}$ Department of Pharmacy, Mawlana Bhashani Science and Technology University, Tangail, \\ Bangladesh
}

Received 1 June 2020, accepted in final revised form 29 September 2020

\begin{abstract}
Bisoprolol is a type of antihypertensive drug ( $\beta$-blocker). It is a poorly water-soluble and highly permeable drug that belongs to class II biopharmaceutical classification. This investigation represents the formulation development of bisoprolol to sustain the drug release. Different types of polymers like hypromellose, xanthan gum, avicel, poly ethylene glycol (PEG) were used in this study. Three different formulations were developed by using different excipients at various ratios. The granules were evaluated for bulk density, tapped density, flow property whereas tablets were evaluated for thickness, hardness, weight variation, compressibility index, uniformity of content, disintegration time, and drug release profile. The concentration of the diffused drug was measured using a UV-visible spectrophotometer at $\lambda_{\max }=225 \mathrm{~nm}$. Granules showed good flow ability and all the formulations passed the quality. Among all the formulations, F-2 and F-3 showed better efficiency. PEG along with hypermellose, and guar gum showed a good combination for sustaining the drug release.
\end{abstract}

Keywords: Bisoprolol; Hypromellose; Sustained release tablet; Release of drug.

(C) 2021 JSR Publications. ISSN: 2070-0237 (Print); 2070-0245 (Online). All rights reserved. doi: http://dx.doi.org/10.3329/jsr.v13i1.47324 J. Sci. Res. 13 (1), 209-219 (2021)

\section{Introduction}

Hypertension is one of the most significant risk factors for cardiovascular disease, especially in the adult population [1]. $\beta$ blockers have been one of the primary treatments of hypertension because of their ability to manage heart failure [2]. Bisoprolol [(RS)-1-\{4[(2-isopropoxyethoxy) methyl]phenoxy\}-3-(isopropylamino)propan-2-ol] is a selective beta-1 receptor blocker administered as effective and safe antianginal agent. Bisoprolol leads to a $46 \%$ decrease in sudden death after one year of administration. It acts essentially through the reduction of myocardial oxygen consumption $[3,4]$.

\footnotetext{
Corresponding author: pharmasalim@yahoo.com
} 
Relatively rapid drug absorption and onset of accompanying pharmacodynamics effects result from immediate-release products. However, plasma drug concentrations decline according to the drug's pharmacokinetic profile after the drug absorption from the dosage form. Eventually, plasma drug concentrations fall below the minimum effective plasma concentration (MEC) resulting in loss of therapeutic activity. Another dose is usually given before this point is reached if a sustained therapeutic effect is desired. In general, conventional dosage forms are more likely to drug plasma level fluctuations (leading to adverse effects or toxicity due to overdoses), high dosage frequency, high dosage requirements, and poor patient compliance.

In recent years, the administration of a drug in a controlled approach is being given greater attention for improved therapeutic levels. Sustained or controlled drug delivery occurs when the drug is released from the polymers at a constant rate for the required period. The polymer, the drug or other active ingredients are combined in such a way that helps in the delayed release [5]. Due to a reduction in the frequency of dosing, the sustained release (SR) dosages form decreases side effects and increases patient compliance. The SR form also maintains constant blood levels and avoids drug plasma level fluctuations associated with conventional immediate-release formulations [6].

As there are limited information about the sustained released dosage form for bisprolol and if the attempt is successful, it will reduce the frequency of drug administration by the hypertensive patients. Taking this in consideration, formulations were prepared by the accession of a release-retarding polymer HPMC shortly hypromellose and other excipients in different proportions. The effects of polymer loading on drug release were recorded after studying the effect of formulae excipient on the disintegration and dissolution time.

\section{Experimental}

\subsection{Materials}

Bisoprolol and hypermellose were a generous gift from Eskayef Pharmaceuticals Ltd, Bangladesh. Magnesium stearate (Merck, Germany), lactose (Loba, India) and xanthan gum (Merck, Germany) were used as received. All other materials were purchased from local markets. Reagents were of analytical grade.

\subsection{Final formulation of Bisoprolol sustained release tablets by direct compression method}

Sustained-release tablets of bisoprolol were prepared by the direct compression method according to the formula given in Table 1. In this method, at first for each formulation batch, the required amount of API (bisoprolol) $75 \mathrm{mg}$ (for 30 tablets) and excipients are weighed by the electronic weighing machine. Then bisoprolol $75 \mathrm{mg}$ is mixed with hypromellose and consequently other excipients like avicel, lactose, xanthan gum, poly ethylene glycol (PEG), guar gum, and Mg stearate are mixed gradually in dry and clean 
mortar. The blend was passed through sieve no. 60. Matrix tablets were prepared by hydraulic press fitted with $13 \mathrm{~mm}$ punch applying a compression pressure of 5 tons. Three formulations have been prepared (F1-F3) in the same process.

Table 1. Formulations (F1-F3) prepared for a single dose.

\begin{tabular}{|l|l|l|l|l|l|l|l|l|l|}
\hline $\begin{array}{l}\text { Formul } \\
\text { ation }\end{array}$ & $\begin{array}{l}\text { Drug } \\
(\mathrm{mg})\end{array}$ & $\begin{array}{l}\text { Hypromel } \\
\text { lose }(\mathrm{mg})\end{array}$ & $\begin{array}{l}\text { Avicel } \\
(\mathrm{mg})\end{array}$ & $\begin{array}{l}\text { Lactose } \\
(\mathrm{mg})\end{array}$ & $\begin{array}{l}\text { Xanthan } \\
\text { gum } \\
(\mathrm{mg})\end{array}$ & $\begin{array}{l}\text { PEG } \\
(\mathrm{mg})\end{array}$ & $\begin{array}{l}\text { Guar } \\
\text { gum } \\
(\mathrm{mg})\end{array}$ & $\begin{array}{l}\text { Mg } \\
\text { stearate } \\
(\mathrm{mg})\end{array}$ & $\begin{array}{l}\text { Total } \\
(\mathrm{mg})\end{array}$ \\
\hline F-1 & 2.5 & 150 & 100 & 150 & 50 & 0 & 50 & 5 & 507.5 \\
\hline F-2 & 2.5 & 200 & 100 & 100 & 50 & 50 & 0 & 5 & 507.5 \\
\hline F-3 & 2.5 & 100 & 100 & 200 & 0 & 50 & 50 & 5 & 507.5 \\
\hline
\end{tabular}

\subsection{Evaluation parameters}

Evaluation of both powder blend and tablets were accomplished under three independent experiments for assuring reproducibility.

\subsubsection{Evaluation of powder blend}

Angle of repose: $20 \mathrm{~g}$ of the sample was taken and it was passed through the funnel from a certain height to obtain the heap. The height of the sample heap formed was measured. The circumference formed was drawn with a pencil on the graph paper. The radius was measured and the angle of repose was determined. This was repeated three times for a sample and calculated by the following formula [7].

$\Theta=\tan ^{-1}(\mathrm{~h} / \mathrm{r})$;

Where, $h$ is height and $r$ is radius.

Bulk density and tapped density: To determine bulk density, a quantity of $4 \mathrm{~g}$ of bisoprolol powder was introduced into a $100 \mathrm{~mL}$ measuring cylinder. The initial volume of the powder was taken. Then the cylinder was allowed to fall under its weight onto a hard surface from a height of $2.5 \mathrm{~cm}$ and allowed to do this for about 50 times. After that, the decreased volume was noted. Bulk density and tapped density can be calculated by using the following formulas [8]:

Bulk density, $\rho b=M / V b$; Tapped density, $\rho t=M / V t$

Where, $M$ is mass of the powder, $V b$ is bulk volume of the powder and $V t$ is final tapping volume of the powder.

Hausner ratio: Hausner ratio is the ratio that is associated with the flow-ability of a powder or granular material [7].

Hausner ratio $=\rho t / \rho b$;

Where, $\rho t$ is tapped density and $\rho b$ is bulk density. 
Carr's Compressibility Index: Carr's Compressibility Index is an indication of the compressibility of a powder. The procedure is to measure the unsettled apparent volume, $\left(V_{0}\right)$, and the final tapped volume, $(V t)$, of the powder after tapping the material until no further volume changes occur. The compressibility index was calculated as follows [8]:

$I=(\rho t-\rho b) / \rho t \times 100$

\subsubsection{Evaluation of tablets}

Weight variation: Twenty tablets were weighed individually and the average weight was calculated. The individual weights were then compared to the average weight. The tablets pass the test if not more than two tablets fall outside the percentage limit and none of the tablets differ by more than double the percentage limit given below [7].

Average of the tablet percentage deviation: $80 \mathrm{mg}$ or less $\pm 10 \%$; More than $80 \mathrm{mg}$ and less than $250 \mathrm{mg} \pm 7.5 \% ; 250 \mathrm{mg}$ or more $\pm 5.0 \%$ (According to British Pharmacopoeia). $\%$ weight variation $=($ Difference between average weight and tablet weight $/$ Average tablet weight) $\times 100$

Hardness: The tablet was placed between a fixed and moving jaw, the body of the Monsanto hardness tester carries an adjustable scale which was set to zero against an index mark fixed to the compression plunger, when the tablet was held between the jaws. The load was gradually increased until the tablet fractured. The value measured in $\mathrm{kgf}$ of the load at the point gave a measure of the tablet [9]. From each batch, three tablets were measured for the hardness and average of six values was noted along with standard deviations [10].

Diameter and thickness: Control of physical dimensions of the tablets such as diameter and thickness is essential for consumer acceptance and tablet uniformity. Twenty tablets from the representative sample were randomly taken and individual tablet thickness and diameter was measured by using digital Vernier Caliper. Average thickness and diameter standard deviation values were calculated.

Compactibility assessment: Here the force required for diametral breaking of the compacts was determined using a hand operated hardness tester (Electrolab EH-01P). The tensile strength $\sigma_{x}$ of the compacts was calculated using the Eq. (1) $[11,12]$.

$\sigma_{x}=\frac{2 x}{\pi d t}$

Where, $x$ is hardness in Kgf, $d$ and $t$ are the diameter and thickness of the compacts in $\mathrm{mm}$ respectively. 
In-Vitro dissolution studies: Dissolution of bisoprolol from various formulations were studied in $900 \mathrm{~mL}$ distilled water at $37{ }^{\circ} \mathrm{C}$ using USP dissolution test apparatus II employing paddle stirrer at $70 \mathrm{rpm}$ for $60 \mathrm{~min}$ [13]. A sample of Sustained Release drug formulation equivalent to a $2.5 \mathrm{mg}$ of bisoprolol was used in each test. At predetermined time intervals, $5 \mathrm{~mL}$ of the sample was withdrawn using a syringe fitted with a pre-filter and simultaneously replaced with fresh $5 \mathrm{~mL}$ dissolution fluid. These collected samples were analyzed for bisoprolol content by measuring the absorbance at $225 \mathrm{~nm}$. Percent of Bisoprolol dissolved at various time intervals was calculated and plotted against time [1416].

\subsection{Analysis of release data}

The release data obtained were treated according to zero-order model (cumulative amount of drug release versus time (h)) describing the system where drug release rate is independent of its concentration, first-order model (log cumulative percentage of drug remaining versus time (h)) describing the release from system where release rate is concentration dependent and Higuchi model (cumulative percentage of drug release versus square root of time (h)) describing the release of drugs from insoluble matrix as a square root of time dependent process based on Fickian diffusion [17].

Zero-order kinetics: Zero-order release would be predicted by the Eq. (2):

$A_{t}=A_{o}-K_{o} t$

Where, $A_{t}$ is drug release at time $t, A_{o}$ is initial drug concentration, and $K_{o}$ is zero-order rate constant $\left(\mathrm{h}^{-1}\right)$.

First-order kinetics: First-order release would be predicted by the Eq. (3):

$\log C=\log C_{o}-K t / 2.303$

Where, $C$ is amount of drug remained at time $t, C_{o}$ is initial amount of drug, and $K$ is Firstorder rate constant $\left(\mathrm{h}^{-1}\right)$.

Higuchi's model: Drug released from the SR devices by diffusion has been described by the Eq. (4) [18]:

$Q=K t^{1 / 2}$

Where $Q$ is amount of drug released at time $t$.

In-vitro disintegration test: Disintegration test of bisoprolol from various formulations were studied on 6 tablets in $600 \mathrm{~mL}$ distilled water at $37^{\circ} \mathrm{C}$ using USP disintegration test apparatus II employing paddle stirrer at $70 \mathrm{rpm}$ for $30 \mathrm{~min}$. One tablet of Sustained Release drug formulation equivalent to a $2.5 \mathrm{mg}$ of bisoprolol was used in each test. After 
$30 \mathrm{~min}$, the thickness and diameter of those tablets are determined. From this decreasing rate of thickness and diameter the disintegration rate can be determined.

Drug content uniformity: Ten tablets were powdered in mortar pestle and the blend equivalent to $100 \mathrm{mg}$ of bisoprolol was weighed and dissolved in $100 \mathrm{~mL}$ of phosphate buffer solutions ( $\mathrm{pH}$ 6.8). The solution was sonicated for $1 \mathrm{~h}$, filtered through Whatman filter paper (No. 1), suitably diluted with $100 \mathrm{~mL}$ of phosphate buffer (pH 6.8). From this resulted solution $1 \mathrm{~mL}$ was taken, diluted to $50 \mathrm{~mL}$ using the same phosphate buffer and absorbance was measured against blank by using double beam UV spectrophotometer (UV-1800 Shimadzu, Japan) at $225 \mathrm{~nm}$ respectively. Each sample was analyzed in triplicate.

The drug content of the tablets was determined according to in-house standards and it meets the requirements if the amount of the active ingredient in each of the 10 tested tablets lies within the range of $90 \%$ to $110 \%$ of the standard amount.

\section{Results and Discussion}

\subsection{Evaluation of tablet blends}

The granules of the different formulations were prepared and evaluated for angle of repose, bulk density, tapped density, Carr's compressibility index and hausner's ratio. The results are presented in the Table 2 . The results of angle of repose and compressibility index $(\%)$ ranged from $\left(21.04^{\circ}\right.$ to $\left.25.12^{\circ}\right)$ and (18.75 to 25.84$)$ respectively. The angle of repose value less than $30^{\circ}$ indicates good flow properties [19]. This was further supported by the lower compressibility index. The lowest compressibility index around $21 \%$ and below is considered to have fair and excellent flow properties [19]. The results of bulk density and tapped bulk density were ranged from (0.417 to 0.449$)$ and (0.513 to 0.606$)$ respectively.

Table 2. Evaluation of mixed blend of drug and excipients.

\begin{tabular}{llllll}
\hline $\begin{array}{l}\text { Formulation } \\
\text { Code }\end{array}$ & $\begin{array}{l}\text { Angle of repose } \\
\left({ }^{\circ}\right)\end{array}$ & $\begin{array}{l}\text { Bulk } \\
\text { density } \\
(\mathrm{g} / \mathrm{mL})\end{array}$ & $\begin{array}{l}\text { Tapped } \\
\text { density } \\
(\mathrm{g} / \mathrm{mL})\end{array}$ & $\begin{array}{l}\text { Carr's index } \\
(\%)\end{array}$ & $\begin{array}{l}\text { Hausner's } \\
\text { ratio }\end{array}$ \\
\hline F-1 & 21.04 & 0.417 & 0.513 & 18.75 & 1.23 \\
F-2 & 25.12 & 0.421 & 0.519 & 18.95 & 1.24 \\
F-3 & 25.02 & 0.449 & 0.606 & 25.84 & 1.35 \\
\hline
\end{tabular}

*The values are expressed as mean

\subsection{Physical characterization and drug content of SR tablets}

The prepared tablets were subjected to preliminary characterization such as physical parameters (thickness, diameter, hardness, tensile strength and weight variation) of all the fabricated tablets. The values are presented in Table 3. All the batches showed uniform 
thickness and diameter. The percentage of average weight variation of each formulation was around $5 \%$, and hence all formulations passed the test for uniformity of weight as per official requirements. The hardness of all the formulations is within the range of limit. So, all the tablet formulations showed acceptable pharmacopoeial properties and complied with pharmacopoeial specifications for weight variation. The tensile strength of the compacts is presented in Fig. 1. The values of tensile strength were changed as a function of polymer concentration in the formulation. When compared with F-1, other formulations showed significant changes $(p<0.05)$ in the tensile strength. This result indicates that hypromellose is good enough to use to solve the problem, where the tablets showed insufficient tensile strength.

Table 3. Physical properties of the tablet formulations.

\begin{tabular}{llllll}
\hline $\begin{array}{l}\text { Formulati } \\
\text { on code }\end{array}$ & $\begin{array}{l}\text { Diameter } \\
(\mathrm{mm})\end{array}$ & $\begin{array}{l}\text { Thickness } \\
(\mathrm{mm})\end{array}$ & $\begin{array}{l}\text { Hardness } \\
(\mathrm{kgf})\end{array}$ & $\begin{array}{l}\text { Tensile strength } \\
\left(\mathrm{kgf} / \mathrm{mm}^{2}\right)\end{array}$ & $\begin{array}{l}\text { Weight variation } \\
(\mathrm{mg})\end{array}$ \\
\hline F-1 & $13.28 \pm 0.022$ & $3.34 \pm 0.033$ & $12.27 \pm 0.194$ & $0.177 \pm 0.010$ & $503 \pm 6.738$ \\
F-2 & $13.31 \pm 0.026$ & $3.33 \pm 0.027$ & $12.71 \pm 0.579$ & $0.187 \pm 0.013$ & $502.8 \pm 1.570$ \\
F-3 & $13.29 \pm 0.029$ & $3.34 \pm 0.029$ & $6.59 \pm 0.640$ & $0.096 \pm 0.011$ & $506.4 \pm 1.030$ \\
\hline
\end{tabular}

*The values are expressed as mean \pm SEM (standard error of mean)

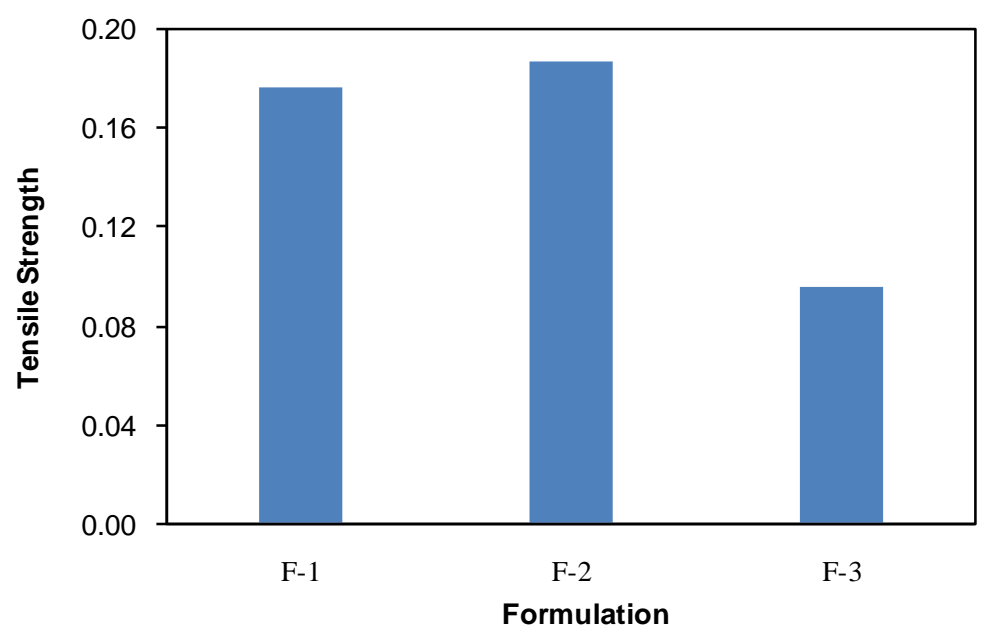

Fig. 1. The tensile strength of bisoprolol SR formulations.

\subsection{Release kinetic studies}

The dissolution data (from the values of 0 to $8 \mathrm{~h}$ drug release) of all formulations were fitted into various mathematical models (zero-order, first-order, Higuchi) to know which mathematical model will best fit the obtained release profile. The plotted figures of zeroorder, first-order and Higuchi were presented in Figs. 2 to 4 . The release kinetics parameters of all formulations were presented in Table 4. Based on highest regression coefficient value $\left(R^{2}\right)$ the best-fit model for all formulations was Higuchi model. When the 
data were plotted according to a Higuchi equation, the formulations F-2 and F-3 showed a fair linearity, with regression values 0.9581 and 0.9782 respectively, while the data were plotted according to a first-order equation, the formulations F-2 and F-3 also showed a fair linearity, with regression values 0.9815 and 0.9823 respectively. These changes may be attributed by the presence of PEG in the formulations. This finding was in accordance with other reported works [20,21]. Moreover, when the Higuchi release rates (Fig. 5) of the formulated tablets were statistically compared with that of F-1, we found a significant $(p<0.05)$ changes of the drug release rate in line with the changes of the polymer concentration in the formulations used in this study. The drug released from the matrix governs the non-fickian mechanism.

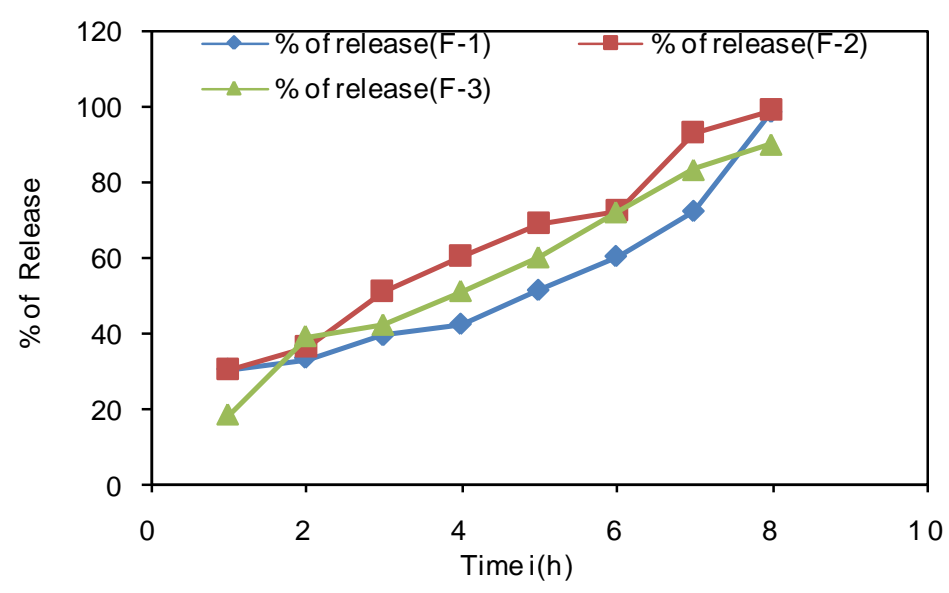

Fig. 2. Percentage of cumulative release at various times (Zero order plot).

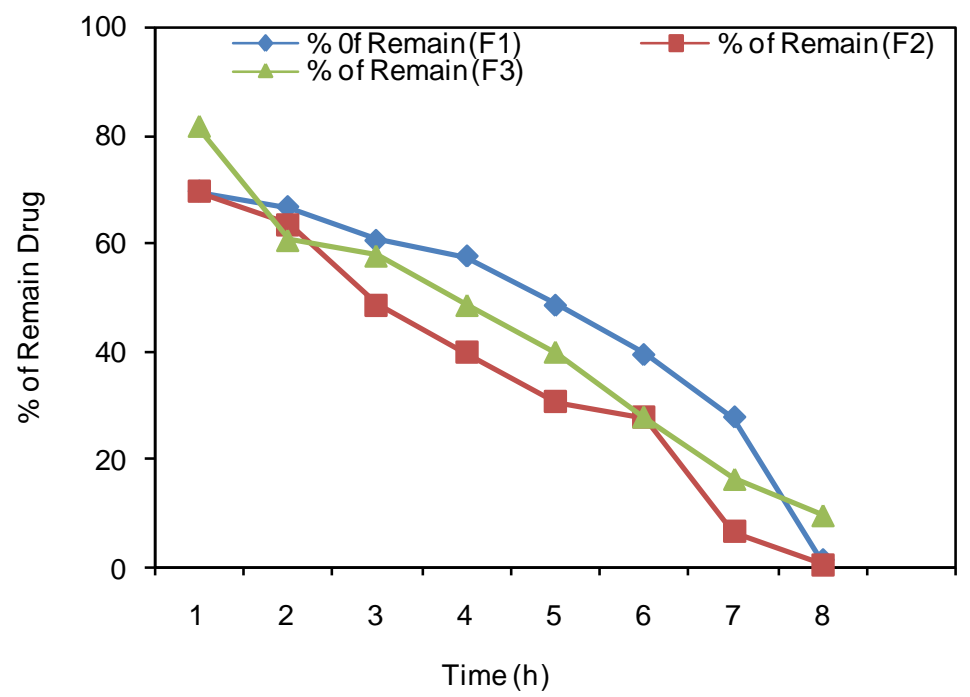

Fig. 3. Percentage of log cumulative remaining drug at various times (First-order plot). 


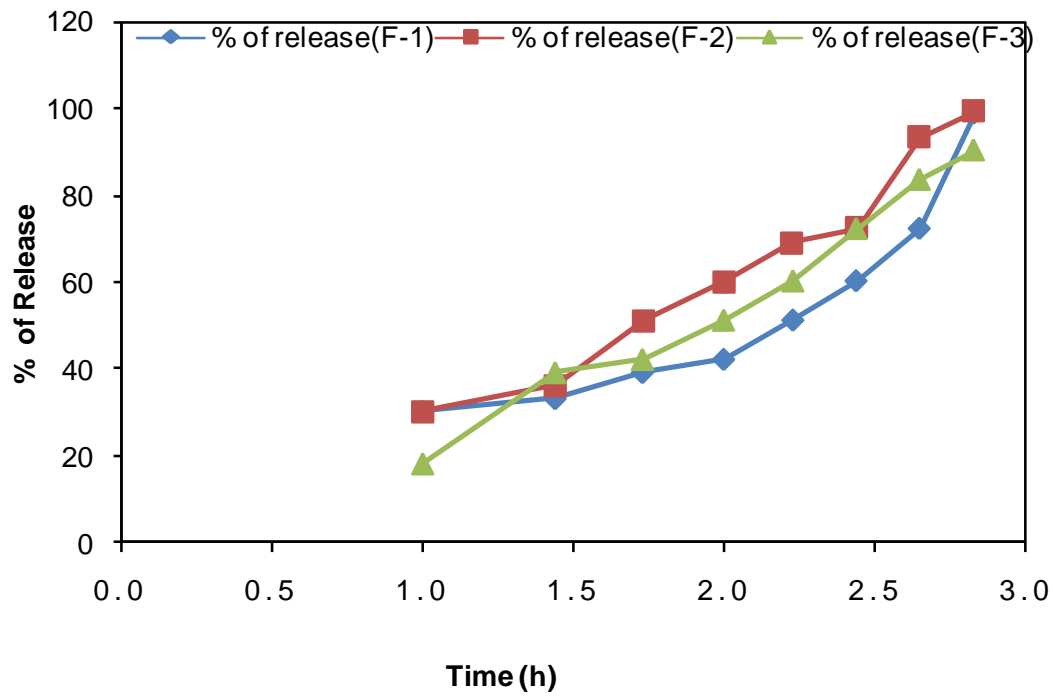

Fig. 4. Percentage of cumulative drug release at $\sqrt{t}_{t}$ time (Higuchi model).

Table 4. Release kinetics parameters at various methods for formulations (F-1-F-3).

\begin{tabular}{llll}
\hline Formulations & In zero order & $\begin{array}{c}\text { Value of } \mathrm{R}^{2} \\
\text { In first order }\end{array}$ & In Higuchi method \\
\hline F-1 & 0.8899 & 0.8899 & 0.8072 \\
F-2 & 0.9815 & 0.9815 & 0.9581 \\
F-3 & 0.9823 & 0.9823 & 0.9782 \\
\hline
\end{tabular}

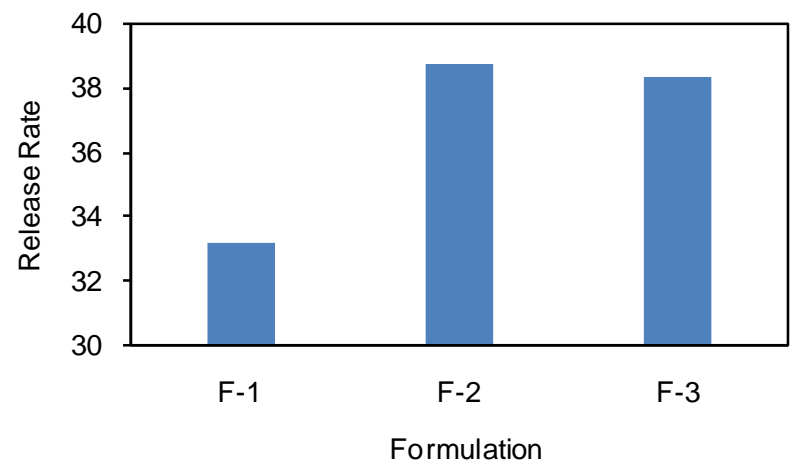

Fig. 5. Bar diagram of Higuchi release rate.

\subsection{Release of drug according to Higuchi equation}

Based on highest regression coefficient value $\left(R^{2}\right)$ the best-fit model for all formulations was Higuchi model. From this experiment, it was observed that the rate of drug release 
changes when the amount of polymer changes and it is statistically significant and presented in Fig. 4. Time required for 25, 50 and $75 \%$ of drug release was corrected using linear equation of Higuchi plot and presented in Table 5. From this study, it was observed that F-2, F-3 took more time for $75 \%$ of drug release.

Table 5. Required time for 25,50 and $75 \%$ of drug release.

\begin{tabular}{llll}
\hline Formulation Code & Time 25\% (h) & Time 50\% (h) & Time 75\% (h) \\
\hline F-1 & 0.75 & 1.51 & 2.26 \\
F-2 & 0.65 & 1.29 & 1.94 \\
F-3 & 0.65 & 1.30 & 1.96 \\
\hline
\end{tabular}

\subsection{Drug content (assay)}

The drug content of all the tablet formulations was analyzed. The results of percent drug content of various formulations are presented in Fig. 6. The percent drug content of all the formulations represented good uniformity and ranges from 75.5 to $91 \%$.

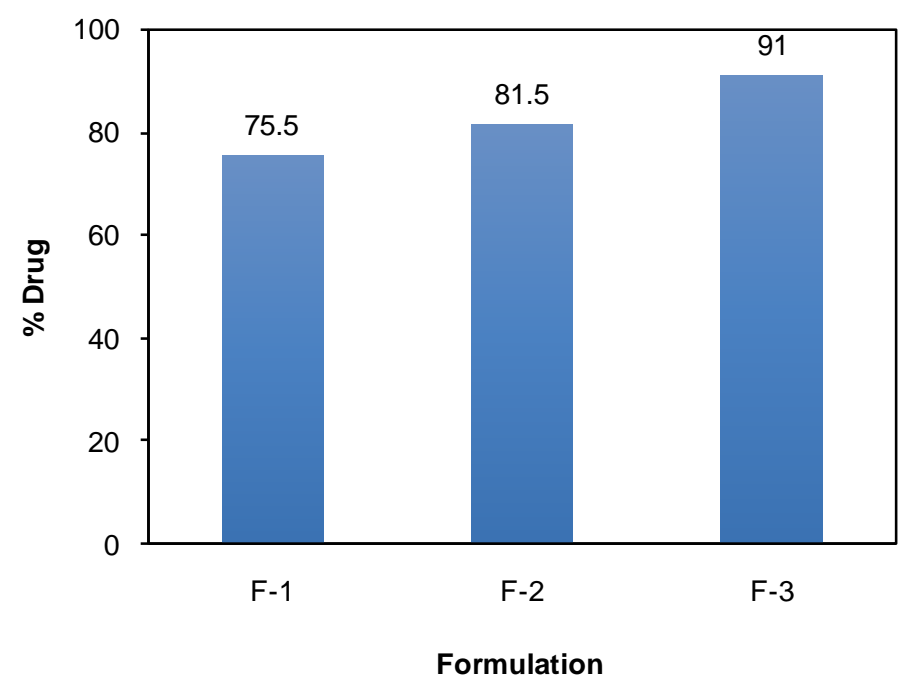

Fig. 6. Percentage assay of the formulations.

\section{Conclusion}

In this study, granules with good flow property were successfully compressed to prepare sustained release formulation. Among all the formulations F-2 and F-3 were good enough in terms of drug release and content. Finally, the present study concluded that the combination of both hydrophilic and hydrophobic polymers could be successfully employed for formulating sustained-release tablets of bisoprolol. However, further 
extensive studies are required to establish good correlation between bioavailability and drug dissolution.

\section{References}

1. M. J. Rathbone, J. Hadgraft, and M. S. Roberts, Modified-Release Drug Delivery Technology, $2^{\text {nd }}$ Edition (Marcel Dekker Inc. New York, 2003) 126, pp. 203. https://doi.org/10.1201/9780203910337

2. I. Y. Dubey and P. L. Starokadomskyy, Int. J. Pham. 308, 149 (2006). https://doi.org/10.1016/j.ijpharm.2005.11.013

3. G. Popa and E. Gafitanu, Rev. Med. Chir. Soc. Med. Nat. Iasi. 107, 337 (2003).

4. M. Serpelloni, Orodispersible Solid Pharmaceutical Form, United States Patent, US 2003/ 0147947 A1 (2003).

5. R. K. Chang, X. Guo, B. A. Burnside, and R. A. Couch. Pharm. Technol. 24, 52 (2000).

6. T. Salsa, F. Veiga, and M. E. Pinna, Drug Develop. Ind. Pharm. 23, 929 (1997). https://doi.org/10.3109/03639049709148697

7. Satyabrathabhanja, P. Ellaiah, S. Martha, Int. J. Pharm. Biomed. Res. 1, 129 (2010).

8. T. S. Owens, R. J. Dansereau, and A. Sakr, Int. J. Pharm. 288, 109 (2005). https://doi.org/10.1016/j.ijpharm.2004.09.017

9. M. E. Aulton, Pharmaceutics: The Science of Dosage form Design, $2^{\text {nd }}$ Edition (Churchill Livingstone, USA, 2002) pp. 457.

10. G. L. Sameer, Y. Yi-Ying, and K. B. Ajay, Int. J. Pharm. 365, 4 (2009). https://doi.org/10.1016/j.ijpharm.2008.08.010

11. J. T. Fell and J. M. Neuton, J. Pharm. Sci. 59, 688 (1970). https://doi.org/10.1002/jps.2600590523

12. M. S. Hossain, S. Banik, and M. S. Islam. Ind. J. Pharm. Edu. Res. 46, 137 (2012).

13. P. Ved, M. Saurabh, S. Deepika, K. Y. Hemlata, and J. Vikas, J. Adv. Pharm. Technol. Res. 2, 223 (2011). https://doi.org/0.4103/2231-4040.90877

14. B. Taylan, Y. Capan, O. Güven, S. Kes, and A. A. Hincal, J. Control. Res. 38, 11 (1996). https://doi.org/10.1016/0168-3659(95)00094-1

15. J. M. Labot, R. H. Manzo, and A. Allemandi, AAPS Pharm. Sci. Technol. 3, 5 (2002).

16. R. W. Korsmeyer and N. A. Peppas, Macromolecular and Modeling Aspects of SwellingControlled Systems, in Controlled Release Delivery Systems, ed. T. J. Roseman et al. (Marcell Dekker, Inc., New York, 1983) pp. 77-90.

17. S. S. Patel, M. R. Patel, and M. J. Patel, J. Sci. Res. 9, 285 (2017). https://doi.org/10.3329/jsr.v9i3.31193

18. T. Kavitha, T. Mangilal, R. Shyamsunder, D. Jayaprakash, A. Ravindranath, and K. S. K. R. Patnaik, Int. J. Cur. Res. 7, 13316 (2015).

19. S. Akbar, R. Bhatta, M. A. Rahman, M. S. Hossain, M. S. Bhuiyan, and M. G. Uddin, J. Sci. Res. 9, 247 (2017). https://doi.org/10.3329/jsr.v9i2.30600

20. F. W. Goodhart, R. H. Mccoy, and F. C. Ninger, J. Pharm. Sci. 63, 1748 (1974). https://doi.org/10.1002/jps.2600631117

21. A. Peterlin, Polym. Eng. Sci. 20, 238 (1980). https://doi.org/10.1002/pen.760200403 